\title{
Online Modelling and Calculation for Operating Temperature of Silicon-Based PV Modules Based on BP-ANN
}

\author{
Honglu Zhu, ${ }^{1,2}$ Weiwei Lian, ${ }^{2}$ Lingxing Lu, ${ }^{2}$ Peter Kamunyu, ${ }^{2}$ Cao Yu, ${ }^{2,3}$ \\ Songyuan Dai, ${ }^{1,2}$ and Yang $\mathrm{Hu}^{1}$ \\ ${ }^{1}$ The State Key Laboratory of Alternate Electrical Power System with Renewable Energy Sources, \\ North China Electric Power University, Changping District, Beijing, China \\ ${ }^{2}$ The School of Renewable Energy, North China Electric Power University, Changping District, Beijing, China \\ ${ }^{3}$ China Three Gorges New Energy Co. Ltd., Beijing, China
}

Correspondence should be addressed to Yang Hu; hooyoung@ncepu.edu.cn

Received 12 July 2017; Revised 2 October 2017; Accepted 11 October 2017; Published 29 November 2017

Academic Editor: K. R. Justin Thomas

Copyright (c) 2017 Honglu Zhu et al. This is an open access article distributed under the Creative Commons Attribution License, which permits unrestricted use, distribution, and reproduction in any medium, provided the original work is properly cited.

The operating temperature of silicon-based solar modules has a significant effect on the electrical performance and power generation efficiency of photovoltaic (PV) modules. It is an important parameter for PV system modeling, performance evaluation, and maximum power point tracking. The analysis shows that the results of physics-based methods always change with seasons and weather conditions. It is difficult to measure all the needed variables to build the physics-based model for the calculation of operating temperature. Due to the above problem, the paper proposes an online method to calculate operating temperature, which adopts the back propagation artificial neural network (BP-ANN) algorithm. The comparative analysis is carried out using data from the empirical test platform, and the results show that both the BP-ANN and the support vector machine (SVM) method can reach good accuracy when the dataset length was over six months. The SVM method is not suitable for the temperature modeling because its computing time is too long. To improve the performance, wind speed should be taken as one of the models' input if possible. The proposed method is effective to calculate the operating temperature of silicon-based solar modules online, which is a low-cost soft-sensing solution.

\section{Introduction}

Since PV power plants mainly adopt silicon-based PV modules throughout the world, the operating temperature is an important parameter which can greatly affect the siliconbased PV modules' electrical performance and efficiency [1]. So the modelling of operating temperature for PV module has arisen great interests of the scholars in recent years. Reference [2] reported that the operating temperature of silicon-based PV modules is affected by external factors such as ambient temperature, wind speed, and solar irradiance. Reference [3] proposed the operating temperature function of silicon-based PV module and established the relationship between operating temperature of PV modules, solar irradiance, and ambient temperature. Reference [4] pointed out a direct relationship between the substantial attenuation of power output of PV system and the operating temperature of silicon-based PV modules and established the relationship between the operating temperature of silicon-based PV modules and the ambient temperature to the output power of PV system. Reference [5] analysed the feasibility of replacement of the operating temperature of silicon-based PV modules with the ambient temperature in terms of the impact on the power generation performance of PV system. Reference [6] studied the relationship among operating temperature coefficient of silicon-based PV modules, solar irradiance, and other factors. The above studies showed clear relationship between the influence of the external environmental factors and the operating temperature. To investigate further the influence from operating temperature to PV modules electrical parameters, [7] pointed out that it was related to the module itself (glazing-cover transmittance, plate absorptance, etc.), the 
geographical and climatic environment where the PV power plant was located, and then analysed the relationship among operating temperature, short-circuit current, and junction current of silicon-based PV modules. Reference [8] pointed out that due to the physical properties of silicon materials, an increase in temperature will cause a decrease in opencircuit voltage and fill factor, leading to a reduced module electrical efficiency. The information reported in [9] is also crucial for the correct positioning of the temperature sensors, and the experimental results showed that typical contemporary panel designs lead to two typical backside convective air temperature profiles which have a direct impact on the effectiveness of natural cooling.

The modelling for operating temperature has attracted more and more attention [10-12], and many researchers have explored the operating temperature calculation methods of silicon-based PV modules. Reference [13] used the theoretical model of silicon-based PV modules to calculate the operating temperature. However, it is very difficult to establish an accurately theoretical model for describing the operating temperature of silicon-based PV modules due to the different material properties and different installation environment of PV plants. Reference [14] proposed a coupled electrical and thermal model of the temperature for photovoltaic (PV) module which uses environmental parameters and electrical variables as input, and the model can be used to judge the health status of the modules. Reference [15] proposed a five multilayer model for the calculation of the operating temperature; however, the model accuracy of the method needs to be improved in practical application. So some researchers started the parameters adjustment works for the models. Reference [16] proposed a linear correlation model for operating temperature of silicon-based PV modules; the parameters were provided by the PV module manufacturers and corrected by experimental test. Reference [17] calculated the operating temperature of siliconbased PV module by modifying the Hottel-Whillier-Bliss (HWB) formula.

Under complicated and poor working condition, the operating temperature of PV module is affected by various factors in reality, which makes it difficult for mechanism model algorithms to describe and solve. But above all, it is impossible to get all the inputs for the mechanism model on site operation. So, for the condition restrictions and the lack of good generalization performance, it is difficult for the physics-based model to be applied in engineering applications.

Regarding the issues above, the paper therefore proposes a method to calculate the operating temperature of siliconbased PV modules using the BP-ANN. For a certain PV plant, the historical data of output power contains information of the plant itself, which involves ambient environment such as solar irradiance, ambient temperature, and internal information regarding to the modules' own characteristic and structure information of power station. The calculation models for operating temperature based on the BP-ANN method using historical data could avoid the complex analysis process of a physics-based model and therefore could be applied to the related engineering calculation effectively.

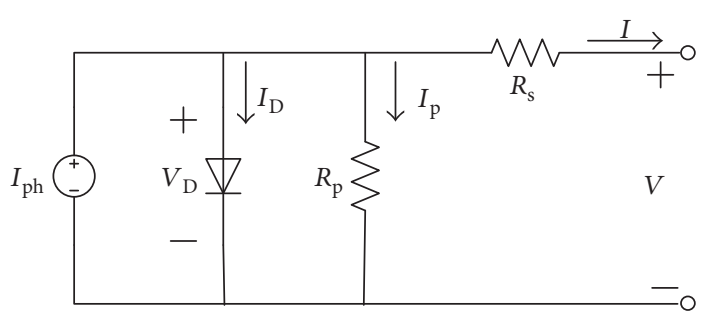

FIGURE 1: Cell equivalent circuit (one exponential model).

The arrangement of the paper is as follows: Section 2 analyses the effect of temperature on the properties of silicon-based PV modules; Section 3 describes the calculation method of PV power generation based on a physics-based model and analyses the error and error sources; in Section 4, the calculation models for operating temperature of silicon-based PV module based on BP-ANN are proposed; in Section 5, the comparative analysis for the performance of the algorithm is analysed; and Section 6 gives the corresponding conclusions.

\section{The Operation Temperature of Silicon-Based PV Modules}

A physics-based model for power generation of PV system applied in engineering is established based on the equivalent circuit of silicon-based solar cell (Figure 1), and the output current of silicon-based solar cell is expressed as follows:

$$
I=I_{\mathrm{ph}}-I_{0}\left[\exp \left(\frac{V+I R_{\mathrm{s}}}{a}\right)-1\right]-\frac{V+I R_{\mathrm{s}}}{R_{\mathrm{p}}}
$$

where $I_{\mathrm{ph}}$ is the photogenic current of silicon-based solar cell; $I_{\mathrm{D}}$ is the diode current; $I_{\mathrm{p}}$ is the current of parallel resistance; and $a$ is the temperature coefficient of short-circuit current.

Considering the change of solar irradiance and temperature under outdoor conditions, the short-circuit current $\left(I_{\mathrm{SC}}\right)$ and open-circuit voltage $\left(V_{\mathrm{OC}}\right)$ of silicon-based solar cells are expressed as follows:

$$
\begin{aligned}
I_{\mathrm{SC}} & =\frac{G}{G_{\mathrm{STC}}} I_{\mathrm{SC} \_\mathrm{STC}}\left[1+a\left(T_{\mathrm{C}}-T_{\mathrm{STC}}\right)\right], \\
V_{\mathrm{OC}} & =V_{\text {OC_STC }}\left[1+\beta\left(G_{\mathrm{STC}}\right)\left(T_{\mathrm{C}}-T_{\mathrm{STC}}\right)\right]\left[1+\delta(T) \ln \frac{G}{G_{\mathrm{STC}}}\right],
\end{aligned}
$$

where $G$ is the solar irradiance of silicon-based solar cell under operating conditions $\left(\mathrm{W} / \mathrm{m}^{2}\right) ; G_{\mathrm{STC}}$ is the solar irradiance under standard test conditions $\left(\left(\mathrm{W} / \mathrm{m}^{2}\right)\right.$ and $\left.G_{\text {STC }}=1000 \mathrm{~W} / \mathrm{m}^{2}\right) ; T_{\mathrm{C}}$ is the operating temperature $\left({ }^{\circ} \mathrm{C}\right)$; $T_{\text {STC }}$ is the module temperature under standard conditions $\left(\left({ }^{\circ} \mathrm{C}\right)\right.$ and $\left.T_{\mathrm{STC}}=25^{\circ} \mathrm{C}\right) ; a$ is the temperature coefficient of short-circuit current, usually provided by the manufacturer; $I_{\text {SC_STC }}$ is the short-circuit current of silicon-based solar cell under standard test conditions; $V_{\text {OC_STC }}$ is the open-circuit voltage of silicon-based solar cell under the standard test 


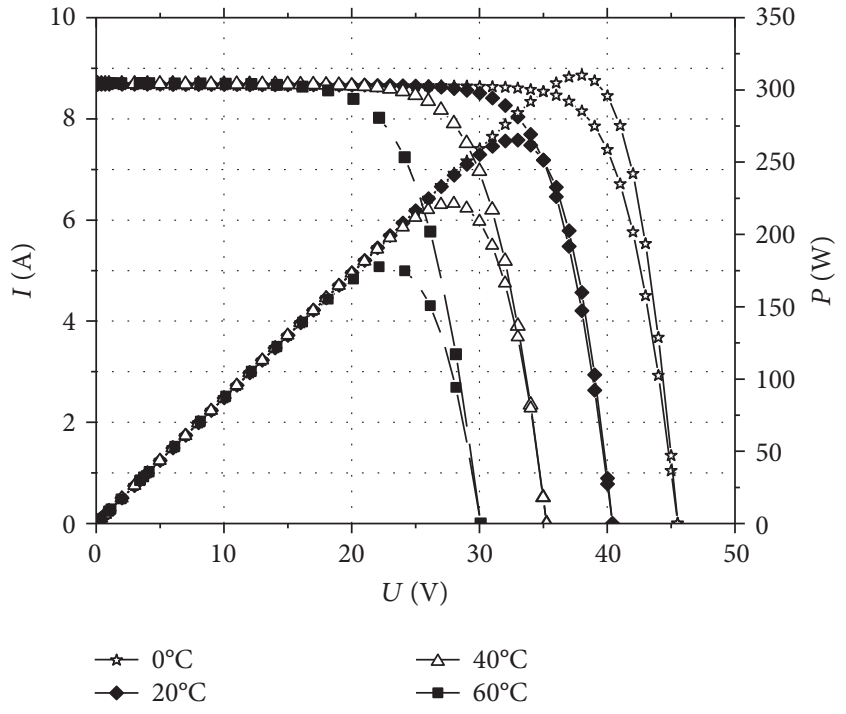

(a) $\left(1000 \mathrm{~W} / \mathrm{m}^{2}\right)$ electrical characteristics of silicon-based solar cells at different temperatures

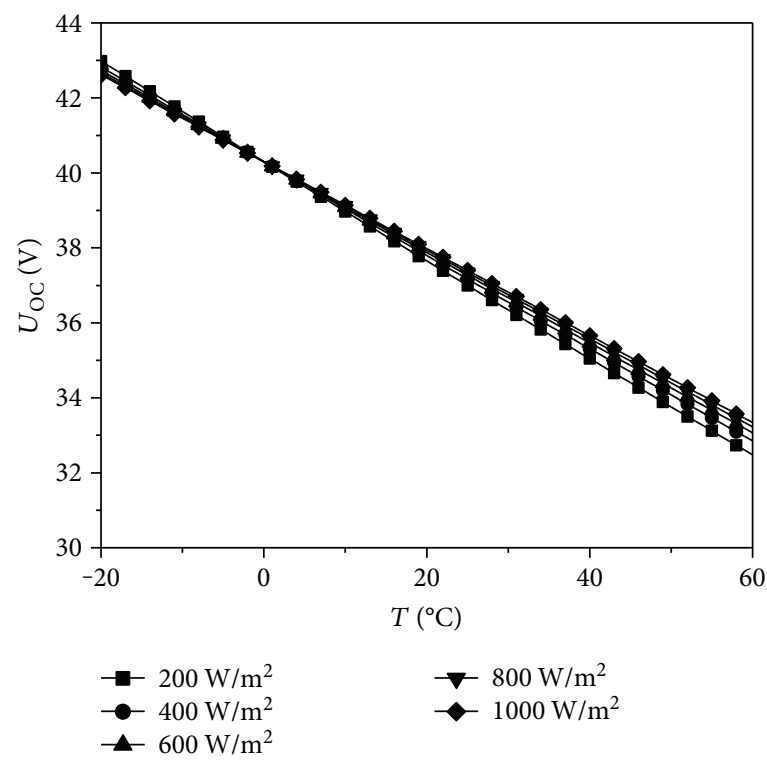

(c) The relationship between the open-circuit voltage of silicon-based solar cells and the temperature or solar irradiance

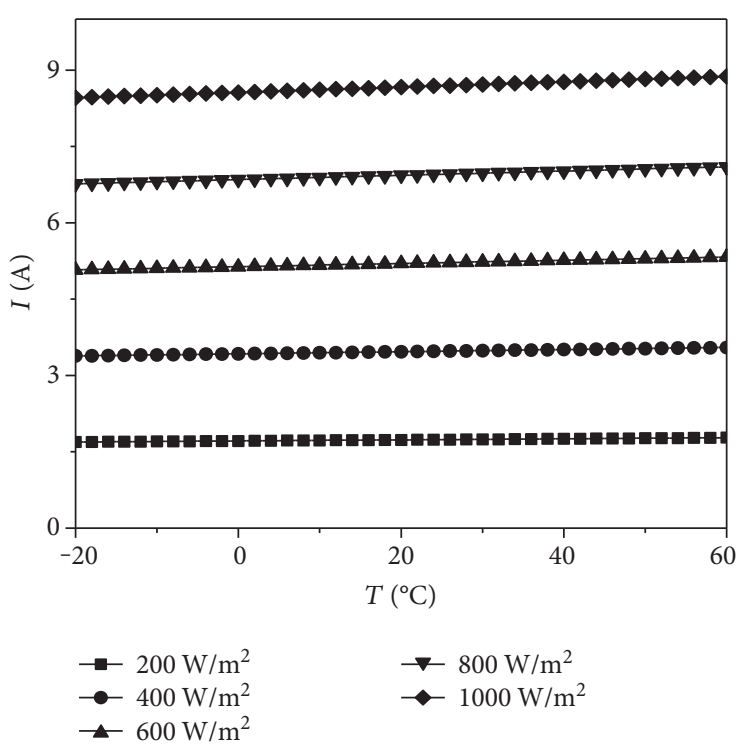

(b) The relationship between short-circuit current of silicon-based solar cell and temperature or solar irradiance

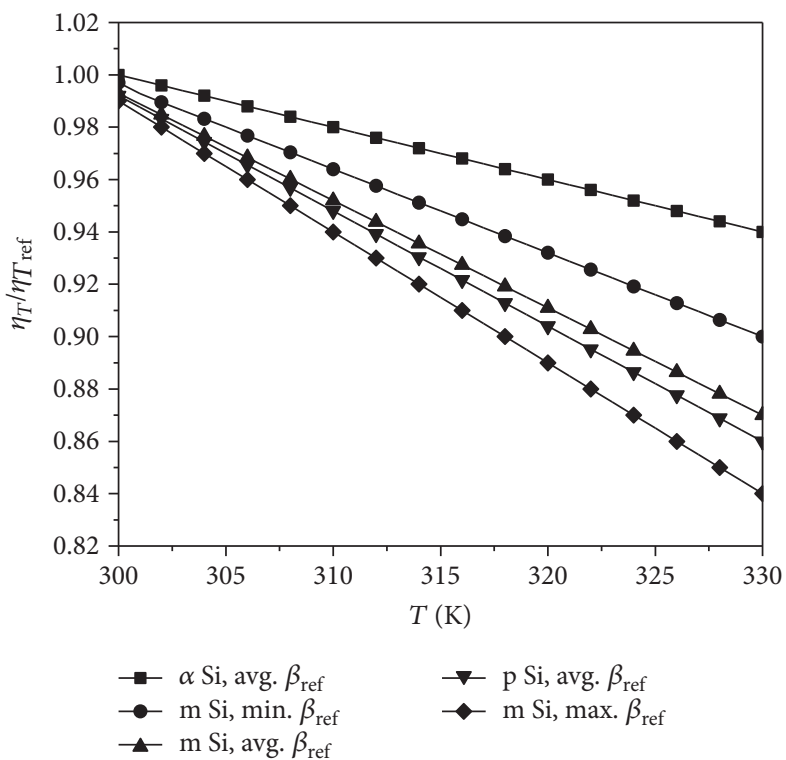

(d) Efficiency ratio of silicon-based solar cell $\left(\eta_{\mathrm{T}} / \eta_{\mathrm{T}_{\mathrm{ref}}}\right)$

FIGURE 2: Effect of temperature on the electrical characteristics and efficiency of PV modules.

conditions; $\beta$ is the temperature coefficient of open-circuit voltage; and $\delta$ is the correction factor of solar irradiance.

Figure 2 illustrates the output characteristics of siliconbased solar cells with changing external environment conditions. As shown in Figures 2(a), 2(b), and 2(c), when the external ambient temperature is constant and solar irradiance changes, the short-circuit current of silicon-based solar cell becomes bigger as solar irradiance increases, while the open-circuit voltage changes smaller, which eventually leads the maximum power point of silicon-based solar cell more stable; when the external solar irradiance is constant and the ambient temperature changes, the short-circuit current of silicon-based solar cell is more stable and the open-
TABLE 1: Performance parameters of silicon-based PV module (JKM245P-60-I).

\begin{tabular}{lc}
\hline PV module $(J K M 245 \mathrm{P}-60-\mathrm{I})$ & \\
\hline Maximum power $\left(P_{\mathrm{m}}\right)$ & $245 \mathrm{kWp}$ \\
Optimum operating voltage $\left(V_{\mathrm{m}}\right)$ & $30.1 \mathrm{~V}$ \\
Optimum operating current $\left(I_{\mathrm{m}}\right)$ & $8.14 \mathrm{~A}$ \\
Open-circuit voltage $\left(V_{\mathrm{OC}}\right)$ & $37.5 \mathrm{~V}$ \\
Short-circuit current $\left(I_{\mathrm{SC}}\right)$ & $8.76 \mathrm{~A}$ \\
Temperature coefficient under open-circuit voltage $\left(V_{\mathrm{OC}}\right)$ & $-0.31 \%$ \\
Temperature coefficient under short-circuit current $\left(I_{\mathrm{SC}}\right)$ & $0.06 \%$ \\
\hline
\end{tabular}


TABLE 2: The electrical equipment configuration of the empirical test platform.

Classes
PV module \begin{tabular}{c}
$\begin{array}{c}\text { Instructions } \\
\text { Optimum operating voltage }\left(V_{\mathrm{m}}\right): 30.1 \mathrm{~V} \\
\text { Optimum operating current }\left(I_{\mathrm{m}}\right): 8.14 \mathrm{~A} \\
\text { Maximum power }\left(P_{\mathrm{m}}\right): 245 \mathrm{kWp}\end{array}$ \\
$\begin{array}{c}\text { Ambient temperature range: }-20^{\circ} \mathrm{C} \sim 60^{\circ} \mathrm{C} \\
\text { AC grid frequency range: } 45 \mathrm{~Hz} \sim 55 \mathrm{~Hz} \\
\text { Nominal DC power: } 2100 \mathrm{~W}\end{array}$ \\
\hline
\end{tabular}

Type number: PZ72L-DE

DC voltmeter

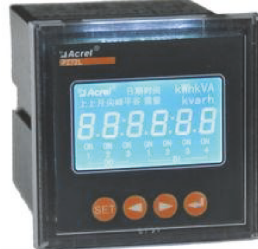

Measuring parameters: DC voltage Modbus-RTU protocol Precision level: 0.5

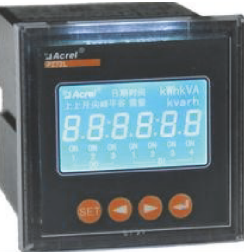

Type number: PZ72L-DE

DC ammeter

Measuring parameters: DC current Modbus-RTU protocol

Precision level: 0.5

AC voltmeter

Type number: PZ72L-AV

Measuring parameters: AC voltage

Modbus-RTU protocol

Precision level: 0.5

AC ammeter


TABLE 2: Continued.

Instructions
Weather station
$\begin{gathered}\text { PT100 sensor } \\ \text { Working environment: }-40 \sim 70^{\circ} \mathrm{C} \\ \text { Relative humidity is less than } 90 \%\end{gathered}$
$\begin{gathered}\text { Precision range: } \pm 0.1^{\circ} \mathrm{C} \\ \text { Sensitivity: } 0.385 \Omega /{ }^{\circ} \mathrm{C} \\ \text { Test range: }-40^{\circ} \mathrm{C}-150^{\circ} \mathrm{C}\end{gathered}$
$\begin{array}{r}\text { Modbus-RTU protocol } \\ \text { PT100 data acquisition unit }\end{array}$

circuit voltage decreases significantly with the external ambient temperature increasing, which eventually leads to the maximum power point of silicon-based solar cell moving to the left side of the axis with the open-circuit voltage decreasing. As a result, as the temperature increases, the open-circuit voltage becomes smaller and the short-circuit current becomes larger, which eventually leads to a decrease in efficiency as shown in Figure 2(d). The specific relationship can be expressed as follows:

$$
\eta=\eta_{\mathrm{STC}}\left[1-\beta_{\mathrm{ref}}\left(T_{\mathrm{C}}-T_{\mathrm{STC}}\right)+\gamma \log _{10} G\right]
$$

where $\eta_{\text {STC }}$ is power generation efficiency of silicon-based solar cells under standard test conditions; $\gamma$ is the solar radiation coefficient; and $\beta_{\text {ref }}$ is the temperature coefficient $\left(\mathrm{K}^{-1}\right)$ at reference conditions. Equations (1), (2), (3), and (4) describe the law change of electrical properties of silicon-based solar cells and their parameters in the external environment, and the parameters in each formula are given by a manufacturer of silicon-based PV modules or required field testing. Due to different production processes by different manufacturers, meeting with different on-site construction conditions and the performance degrades of silicon-based PV modules under long-term outdoor condition results in distortion of PV module parameters. Meanwhile, due to the restrictions of site conditions of the PV power plant, the actual parameters of silicon-based PV modules cannot be obtained by the test method; hence, it can only be obtained by an indirect method, which leads to a large deviation between the calculated values and the actual ones.

\section{Calculation and Empirical Analysis of the Operating Temperature of Silicon-Based PV Modules}

3.1. Calculation for the Operating Temperature of SiliconBased PV Modules. The operating temperature of siliconbased PV modules has an impact on the output power of the PV plant in practical applications. With the increase in the operating temperature of silicon-based PV modules, the excited state electrons dominate the electrical characteristics of the semiconductor, which shows that the open-circuit voltage and filling factor of the modules are reduced greatly while the short-circuit current grows slightly, and finally the overall performance is a degraded output in terms of power and efficiency [2]. In engineering applications, the relationship between the output power and the operating temperature of the silicon-based PV modules can be described as follows:

$$
P_{T_{\mathrm{c} \_\mathrm{r}}}=\eta_{\text {ref }}\left[1-\beta_{\text {ref }}\left(T_{\mathrm{c}}-T_{\text {ref }}\right)\right] \times G_{\mathrm{T}} \times A,
$$

where $\beta_{\text {ref }}$ is the temperature coefficient of silicon-based PV modules, which generally is $0.004 \mathrm{~K}^{-1}$, and $T_{\mathrm{c}}$ is the operating temperature of silicon-based PV modules. Through the formula, we can see that the operating temperature of silicon-based modules is an important parameter for the operation of PV power generation system, but it is unrealistic to install the temperature collector for each module of large-scale PV plants. The operating temperature of PV modules is difficult to obtain under actual environment conditions. 

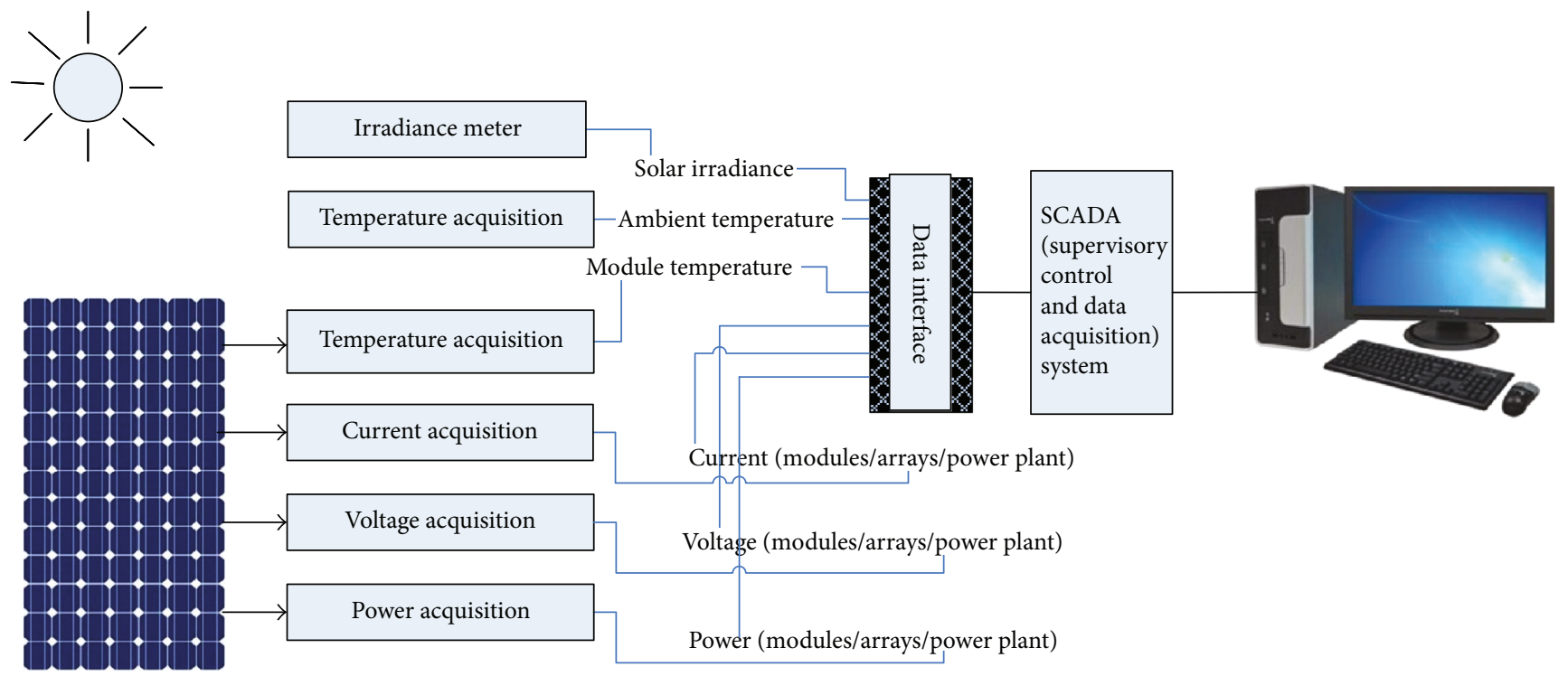

FIgURE 3: The system structure of the empirical test platform.

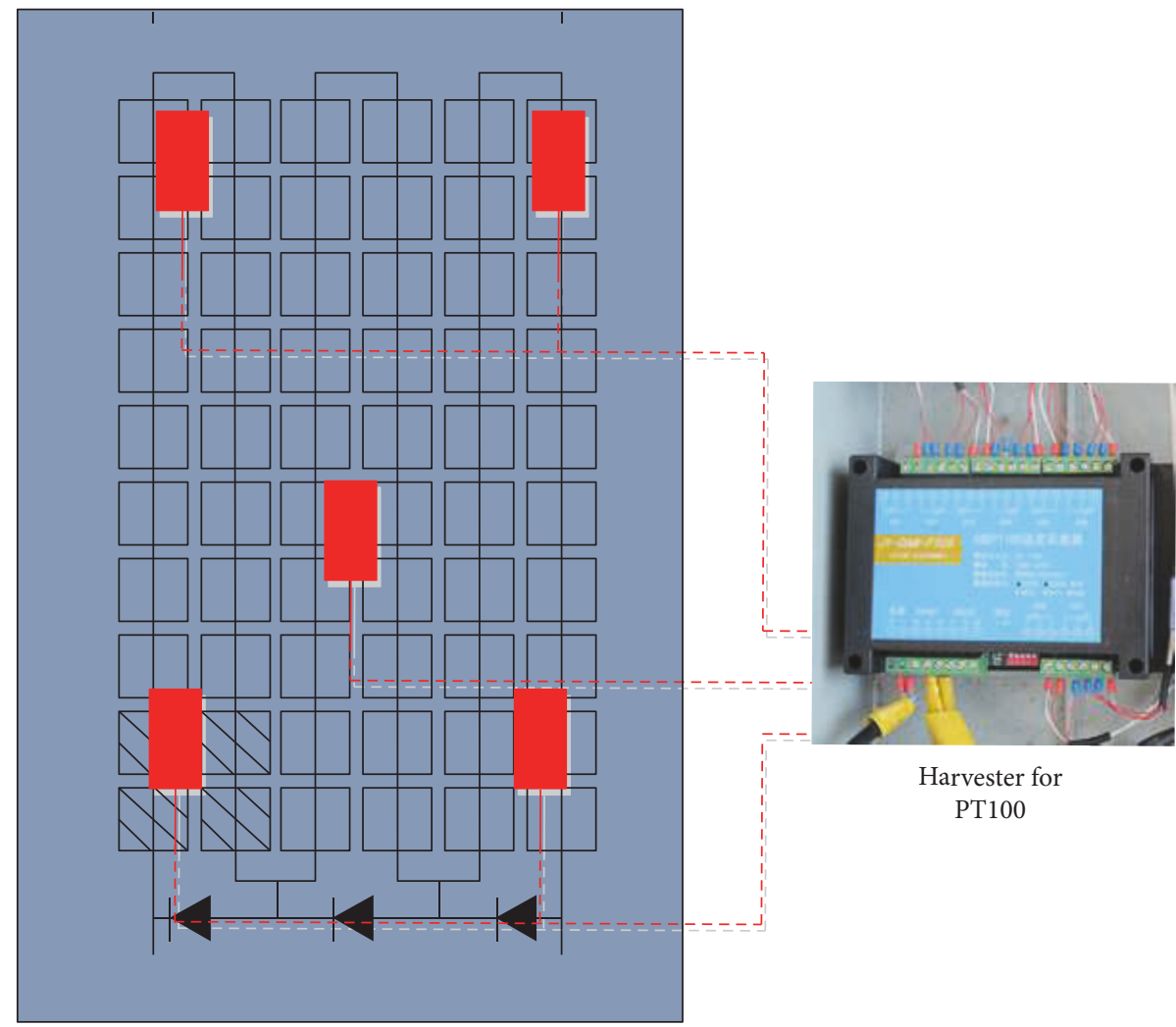

FIGURE 4: The temperature sensor arrangement of the empirical test platform.

For the shortcomings of complex and long-time calculation using for most physics-based models, they are difficult for the online temperature calculation. So the model proposed by Wysocki and Rappaport [7] is used for the comparative analysis in the paper. In practical applications, the relationship between the operating temperature of siliconbased PV modules and the ambient temperature can be simply described as follows:

$$
T_{\mathrm{c}}=T_{\mathrm{a}}+\left(\frac{G_{\mathrm{T}}}{G_{\mathrm{NOCT}}}\right)\left(T_{\mathrm{NOCT}}-T_{\mathrm{a}, \mathrm{NOCT}}\right),
$$

where $T_{\mathrm{a}}$ is ambient temperature and $T_{\mathrm{NOCT}}$ is nominal operating cell temperature of silicon-based solar cells.

3.2. Description of the Empirical Platform. The silicon-based PV modules analysed in the paper are JKM245P modules, 

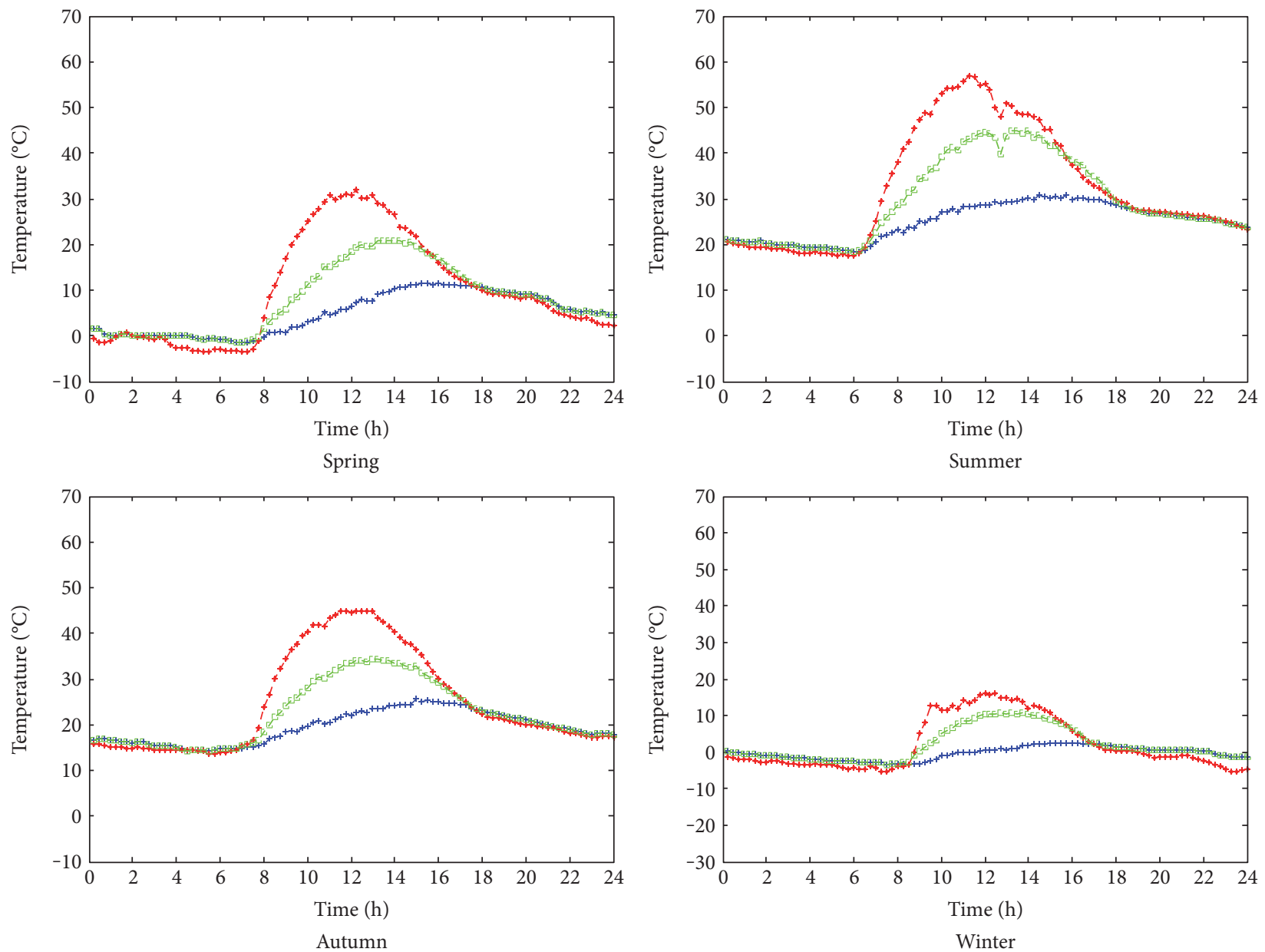

$$
\begin{aligned}
& -+-T_{\mathrm{a}} \\
& -+-T_{\mathrm{c} \_\mathrm{r}} \\
& -\oplus-T_{\mathrm{c} \_\mathrm{cal}}
\end{aligned}
$$

FIGURE 5: Calculation and analysis for operating temperature of silicon-based PV modules under typical seasonal condition.

with a reference module efficiency $\left(\eta_{\text {ref }}\right)$ that is $14.97 \%$, reference temperature $\left(T_{\text {ref }}\right)$ that is $25^{\circ} \mathrm{C}$, and nominal operating cell temperature of silicon-based solar cells $\left(T_{\text {NOCT }}\right)$ that is $45^{\circ} \mathrm{C}$.

In order to evaluate the performance of the above proposed method of operating temperature for PV power generation system, an empirical test platform is constructed. The platform's installed capacity is $9.555 \mathrm{kWp}$. A total of 39 JKM245P-60-I PV modules are used, and the electrical parameters are shown in Table 1 . The platform is equipped with SCADA (supervisory control and data acquisition) system, which can collect multiple operating parameters of a PV plant such as the PV power generation, the current of AC and DC sides, and the voltage of AC and DC sides. At the same time, in order to better analyse the influence of external environment on operating temperature and performance, a small weather station is equipped, which can measure the external environmental parameters such as global solar irradiance, temperature, and wind speed. Moreover, an operating temperature test system of PV modules is built. The system consists of two PT100 temperature collectors, each of which is
TABLE 3: Error analysis about calculation for the operating temperature of silicon-based PV modules in typical seasons.

\begin{tabular}{lccccc}
\hline \multirow{2}{*}{ Classes } & & \multicolumn{4}{c}{ Temperature analysis } \\
& & Spring & Summer & Autumn & Winter \\
\hline \multirow{2}{*}{ MaxError } & $T_{\text {c_cal }}\left({ }^{\circ} \mathrm{C}\right)$ & 15.65 & 14.56 & 12.32 & 10.26 \\
& $T_{\mathrm{a}}\left({ }^{\circ} \mathrm{C}\right)$ & 26.05 & 28.77 & 23.17 & 15.70 \\
\multirow{2}{*}{ STD } & $T_{\text {c_cal }}\left({ }^{\circ} \mathrm{C}\right)$ & 4.56 & 4.62 & 4.31 & 1.90 \\
& $T_{\mathrm{a}}\left({ }^{\circ} \mathrm{C}\right)$ & 8.55 & 9.88 & 8.31 & 4.96 \\
\multirow{2}{*}{ RMSE } & $T_{\text {c_cal }}\left({ }^{\circ} \mathrm{C}\right)$ & 10.79 & 5.88 & 7.02 & 11.04 \\
& $T_{\mathrm{a}}\left({ }^{\circ} \mathrm{C}\right)$ & 19.67 & 12.77 & 13.33 & 12.31 \\
\multirow{2}{*}{ MAE } & $T_{\text {c_cal }}\left({ }^{\circ} \mathrm{C}\right)$ & 7.08 & 3.66 & 4.42 & 8.81 \\
& $T_{\mathrm{a}}\left({ }^{\circ} \mathrm{C}\right)$ & 12.42 & 8.16 & 8.21 & 8.57 \\
\hline
\end{tabular}

connected to eight PT100 temperature sensors installed to the back of the PV modules. Table 2 illustrates the electrical equipment configuration of the empirical test platform. Figure 3 illustrates the system structure of the empirical test platform. Figure 4 illustrates the temperature sensor 


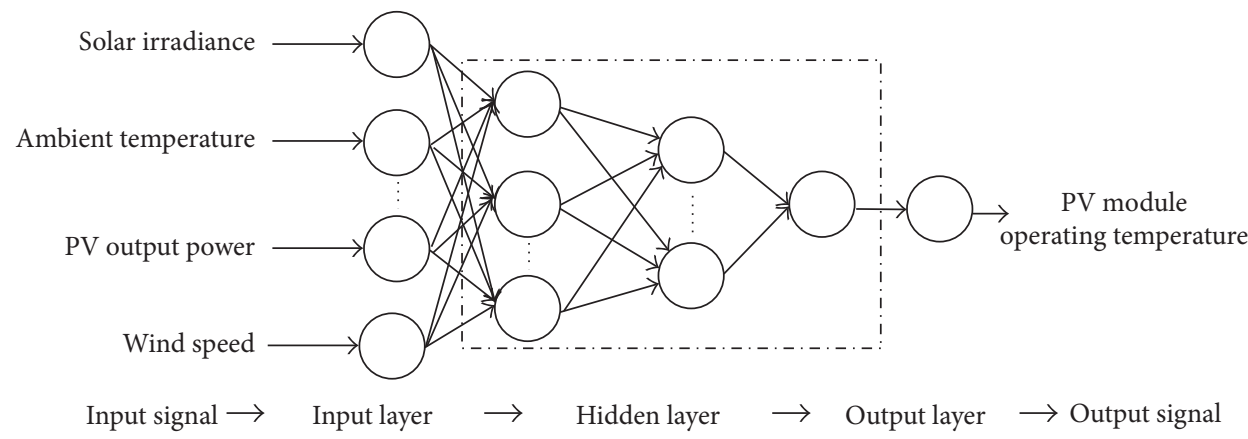

FIGURE 6: The structure of BP neural network.

arrangement. The analysis process in the paper collects the average of each temperature measurement point.

3.3. Empirical Analysis. In order to show the performance of the above different temperatures, the measured solar radiation on tilted PV module and ambient temperature are taken as inputs. The operating temperatures of silicon-based PV modules are calculated, which are based on the empirical formula (6). Figure 5 shows the calculation results of temperature.

In order to quantify the performance of operating temperature of PV modules, the indicators below are selected to evaluate the results, such as the maximum error (MaxError), standard deviation (STD), root mean square error (RMSE), and mean absolute error (MAE). The corresponding equations are as follows:

$$
\begin{gathered}
\text { MaxError }=\max \left(X_{\mathrm{obs}, i}-X_{\mathrm{C}, i}\right), \\
\mathrm{STD}=\frac{\sum_{i=1}^{n}\left(X_{\mathrm{C}, i}-X_{\text {mean }}\right)^{2}}{n}, \\
\mathrm{RMSE}=\sqrt{\frac{\sum_{i=1}^{n}\left(X_{\mathrm{obs}, i}-X_{\mathrm{C}, i}\right)^{2}}{n},} \\
\mathrm{MAE}=\frac{\sum_{i=1}^{n}\left|X_{\mathrm{C}, i}-X_{\text {mean }}\right|}{n},
\end{gathered}
$$

where $X_{\mathrm{obs}, i}$ is actual observation value of PV plant under operating condition; $X_{\mathrm{C}, i}$ is calculated values of the corresponding models; $X_{\text {mean }}$ is arithmetic mean of the calculated values of the corresponding models; and $n$ is the number of samples. The results of the quantitative analysis including nighttime are shown in Table 3.

The following conclusions can be obtained from Figure 5 and Table 3: the physics-based model for the operating temperature of silicon-based PV module can describe the trend of operating temperature, but there is a large error.

\section{Calculation Method of Operating Temperature of Silicon-Based PV Modules Based on BP-ANN}

4.1. BP-ANN. In the paper, BP-ANN is used for modelling and

\begin{tabular}{|c|c|c|}
\hline \multicolumn{2}{|c|}{ Calculation modules } & $\begin{array}{l}\text { PV module operating } \\
\text { temperature }\end{array}$ \\
\hline \multicolumn{2}{|c|}{ Input parameters } & $\begin{array}{c}\text { Solar irradiance } \\
\text { Ambient temperature } \\
\text { Wind speed (optional) }\end{array}$ \\
\hline \multirow{3}{*}{$\begin{array}{l}\text { The number } \\
\text { of neurons }\end{array}$} & The first hidden layer & 50 \\
\hline & The second hidden layer & 30 \\
\hline & The third hidden layer & 1 \\
\hline
\end{tabular}
analysis. BP-ANN refers to the multilayer forward neural network based on an error back propagation algorithm. Its essence
TABle 4: Parameter configuration list of the calculation model.

is to study the statistical data and find out the rules between the data and then calculate it. The main difficulty of BP-ANN built is to determine the number of hidden layers and hidden layer nodes of neural network. In the structure of BP-ANN, the number of hidden layers and hidden layer nodes affects the calculation results of the model to a great extent. If the number is too large, it will increase the calculation and lengthen training time. If the number is too small on the other hand, it will reduce the accuracy of the calculation results. At present, there is no perfect theoretical method to determine the number of hidden layers and hidden layer nodes of BP-ANN. The most commonly used method is the trial and error method. The optimal structure of neural network is determined by repeated experiments. Therefore, BP-ANN has a self-learning ability and it can adjust its own parameters to achieve the adaptive mapping of between output power of PV plant and solar irradiance and operating temperature of $\mathrm{PV}$ module.

Step 1. Calculate all the hidden layer nodes from the outputs.

$$
\begin{aligned}
Y_{j} & =f_{1}\left(\sum_{i=1}^{n} w_{i j}+b_{j}\right)=f_{1}\left(\text { net }_{j}\right) \\
\text { net }_{j} & =\sum_{i=1}^{n} W_{i j} Y_{j}+b_{j}, \\
& \quad i=1, \ldots, n ; j=1, \ldots, 2 n+1
\end{aligned}
$$

where net ${ }_{j}$ is the activation value of node $j, W_{i j}$ represents the connection weight from input node $i$ to hidden node $j, b_{j}$ 
TABle 5: Setup of dataset.

\begin{tabular}{|c|c|c|c|c|c|c|}
\hline & 7 days & 15 days & 1 month & 3 months & 6 months & One year \\
\hline Group 1 & Jan 1-7 & Jan $1-15$ & Jan 1-31 & Jan-Mar & Jan-Jun & Except for Jan \\
\hline Group 2 & Mar 1-7 & Mar 1-15 & Mar 1-31 & Mar-May & July-Dec & Except for Mar \\
\hline Group 3 & May 1-7 & May 1-15 & May 1-31 & May-July & Odd months & Except for May \\
\hline Group 4 & July 1-7 & July 1-15 & July 1-31 & July-Sept & Even months & Except for July \\
\hline Group 5 & Sept $1-7$ & Sept $1-15$ & Sept $1-30$ & Sept-Nov & $1,2,5,6,9,10$ & Except for Sept \\
\hline Group 6 & Nov $1-7$ & Nov $1-15$ & Nov $1-30$ & Nov-Jan & $3,4,7,8,11,12$ & Except for Nov \\
\hline
\end{tabular}

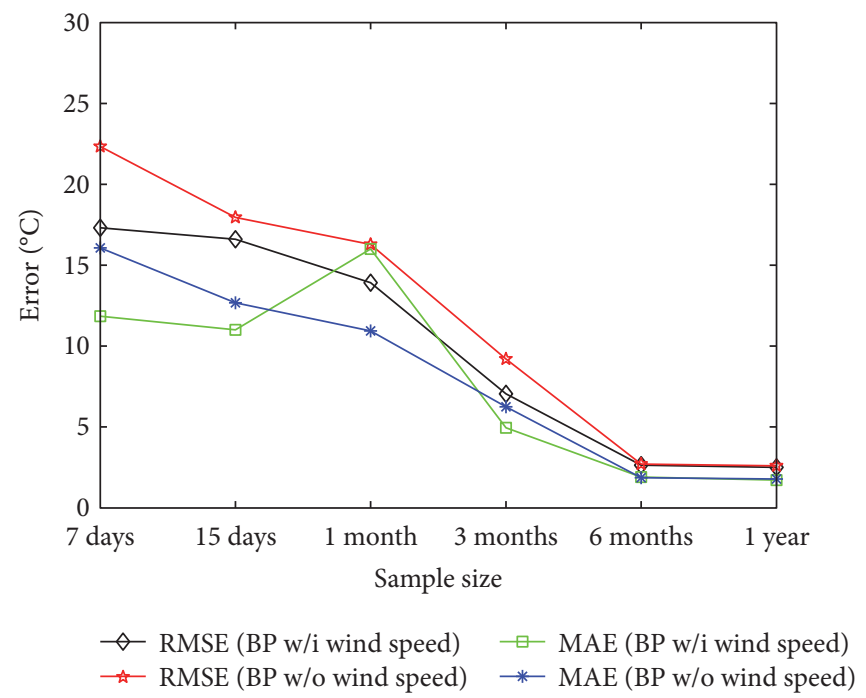

FIGURE 7: Modelling result of BP-ANN (w/i or w/o wind speed).

represents the bias of neuron $j, Y_{j}$ represents the output of hidden layer node $j$, and $f_{1}(\cdot) f$ is the activation function of a node. $f_{1}(\cdot)$ is often a sigmoid function.

Step 2. Calculate the output data of the neural network.

$$
O_{\text {net }}=f_{2}\left(\sum_{j=1}^{2 n+1} W_{o j} Y_{j}+b_{o}\right), \quad j=1, \ldots, 2 n+1
$$

where $W_{o j}$ represents the linkage weight from hidden node $j$ to output node $o, b_{o}$ represents the bias of the neuron, $O_{\text {net }}$ represents the output data of network, and $f_{2}(\cdot)$ is the activation function of output layer node.

Step 3. Minimize the global error $E$ by using the training algorithm.

$$
E=\frac{1}{2} \sum\left(O_{\text {net }}-O_{\mathrm{r}}\right)^{2}
$$

where $O_{\mathrm{r}}$ is the real output of testing data.

Step 4. If the above error is smaller than the preset error, the training process stops. If not, this process returns to Step 1 to continue the training till each global error is smaller than the preset error.
4.2. Calculation Model of Operating Temperature of SiliconBased PV Modules Based on BP-ANN. According to the presented neural network structure in Figure 6, calculation models for the operating temperature of PV module are established. It can be seen from Figure 2 that the operating temperature of silicon-based PV modules is related to the ambient temperature, the output power of PV system, solar irradiance, and other parameters. However, the operating temperature model of silicon-based PV modules established by the physics-based modelling method is very complicated and some variables and parameters in the model are hard to obtain. Therefore, this paper adopts the BP-ANN method to establish the calculation model for operating temperature of PV modules and constructs a five-layer BP-ANN model, choosing solar irradiance, ambient temperature, and PV output power as input variables of the BP-ANN model. The wind speed will affect the operating temperature of the PV modules, where the wind speed is used as an alternative input of the model. The parameters of the operating temperature model of siliconbased PV modules based on BP-ANN are shown in Table 4.

\section{Result and Discussion}

5.1. Setup of Training Dataset. To illustrate the effect of the length of training dataset on model accuracy, different training datasets described in Table 5 are used for the modelling. 


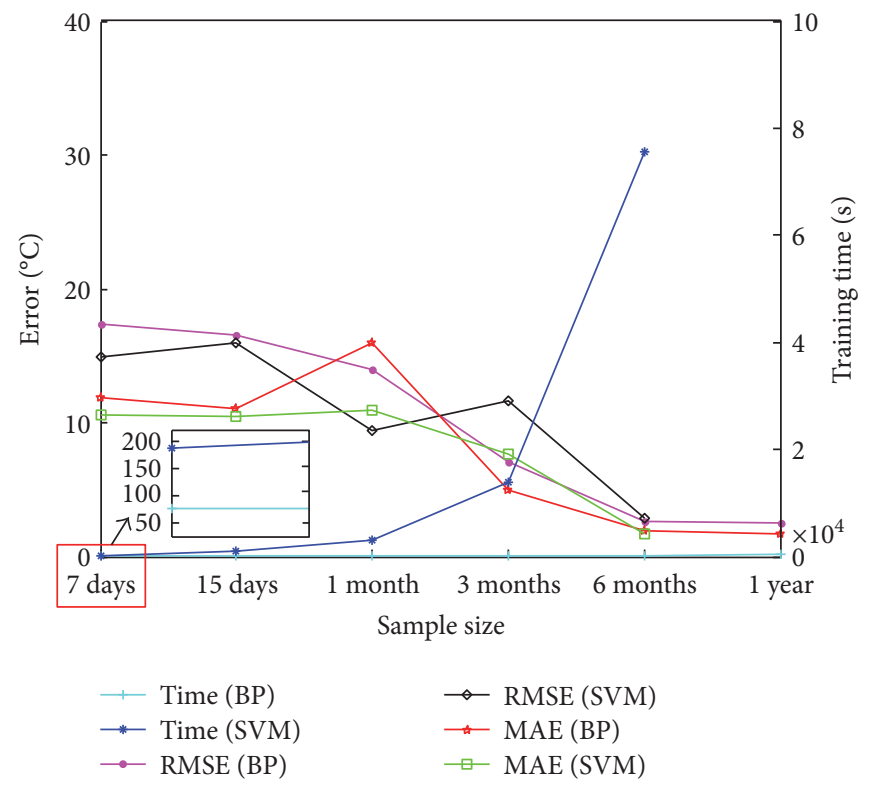

Figure 8: Comparison of different models' performance.

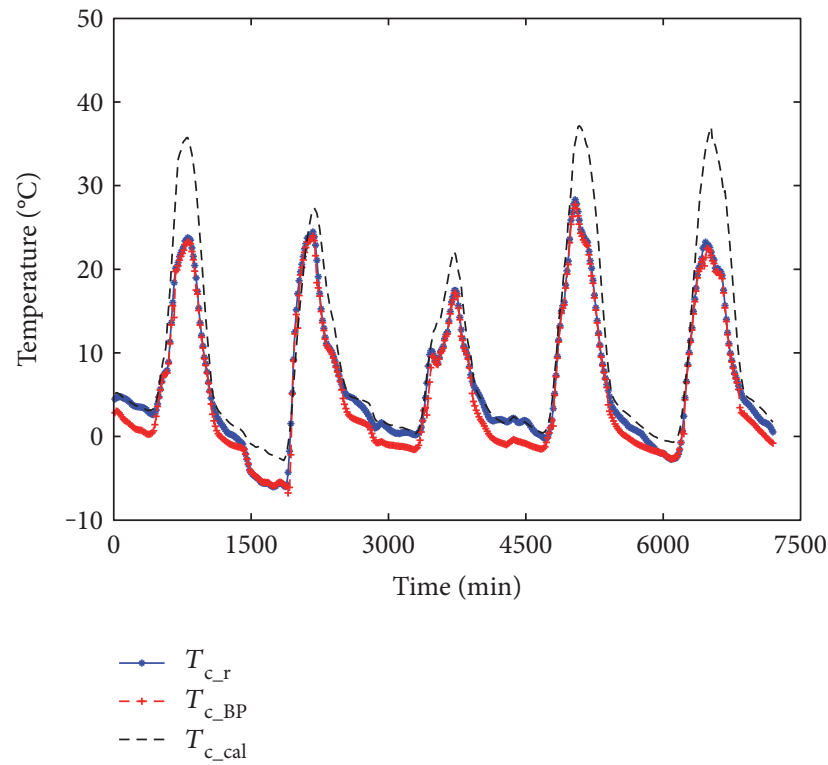

FIGURE 9: Calculation results of operating temperature of siliconbased PV modules.

For comparison, the full year data of 2016 was divided into 6 groups and statistical analysis is made. The percentage of historical data used for the training model is 0.8 , and the percentage of test data is 0.2 .

5.2. Comparative Analysis. According to the parameter setting in Table 4, the calculation models of silicon-based PV module operating temperature using BP-ANN are set up, which will be divided into two groups taking into account the impact of wind speed. From Figure 7, we can see that the wind speed is of help to get a better calculation result for operating temperature of PV modules, so the wind speed should be taken as the model's input if it is allowed.
TABLE 6: Error analysis.

\begin{tabular}{lcccccc}
\hline \multirow{2}{*}{ ClasClasses } & \multicolumn{5}{c}{ Temperature analysis } \\
& & Day 1 & Day 2 & Day 3 & Day 4 & Day 5 \\
\hline \multirow{2}{*}{ MaxError $\left({ }^{\circ} \mathrm{C}\right)$} & $T_{\text {c_cal }}$ & 13.05 & 8.40 & 6.23 & 12.72 & 15.29 \\
& $T_{\text {c_BP }}$ & 3.70 & 4.25 & 3.59 & 2.62 & 2.08 \\
\multirow{2}{*}{ STD $\left({ }^{\circ} \mathrm{C}\right)$} & $T_{\text {c_cal }}$ & 4.45 & 1.98 & 1.94 & 4.22 & 4.92 \\
& $T_{\text {c_BP }}$ & 1.03 & 0.99 & 1.03 & 0.93 & 0.71 \\
\multirow{2}{*}{ RMSE $\left({ }^{\circ} \mathrm{C}\right)$} & $T_{\text {c_cal }}$ & 8.82 & 3.83 & 3.35 & 6.97 & 8.50 \\
& $T_{\text {c_BP }}$ & 2.26 & 1.31 & 2.22 & 1.68 & 1.11 \\
MAE $\left({ }^{\circ} \mathrm{C}\right)$ & $T_{\text {c_cal }}$ & 5.72 & 3.16 & 2.21 & 4.58 & 5.94 \\
& $T_{\text {c_BP }}$ & 1.63 & 0.73 & 1.78 & 1.21 & 0.68 \\
\hline
\end{tabular}

To verify the good performance of the proposed BPANN model, the SVM model is built for the comparison, and the results are shown in Figure 8. The following conclusions can be obtained based on comparison analysis.

(1) With the increase of training dataset length, the computational accuracies for BP-ANN and SVM model both are raised.

(2) With the increase of training dataset length, the SVM method is no longer fit for temperature modelling for its long training time (the analysis of the SVM is not retained for one year).

(3) The proposed methods based on BP-ANN with wind speed is superior to the SVM-based model.

The above analysis shows that the proposed model is feasible with higher calculation accuracy and faster calculation speed. 

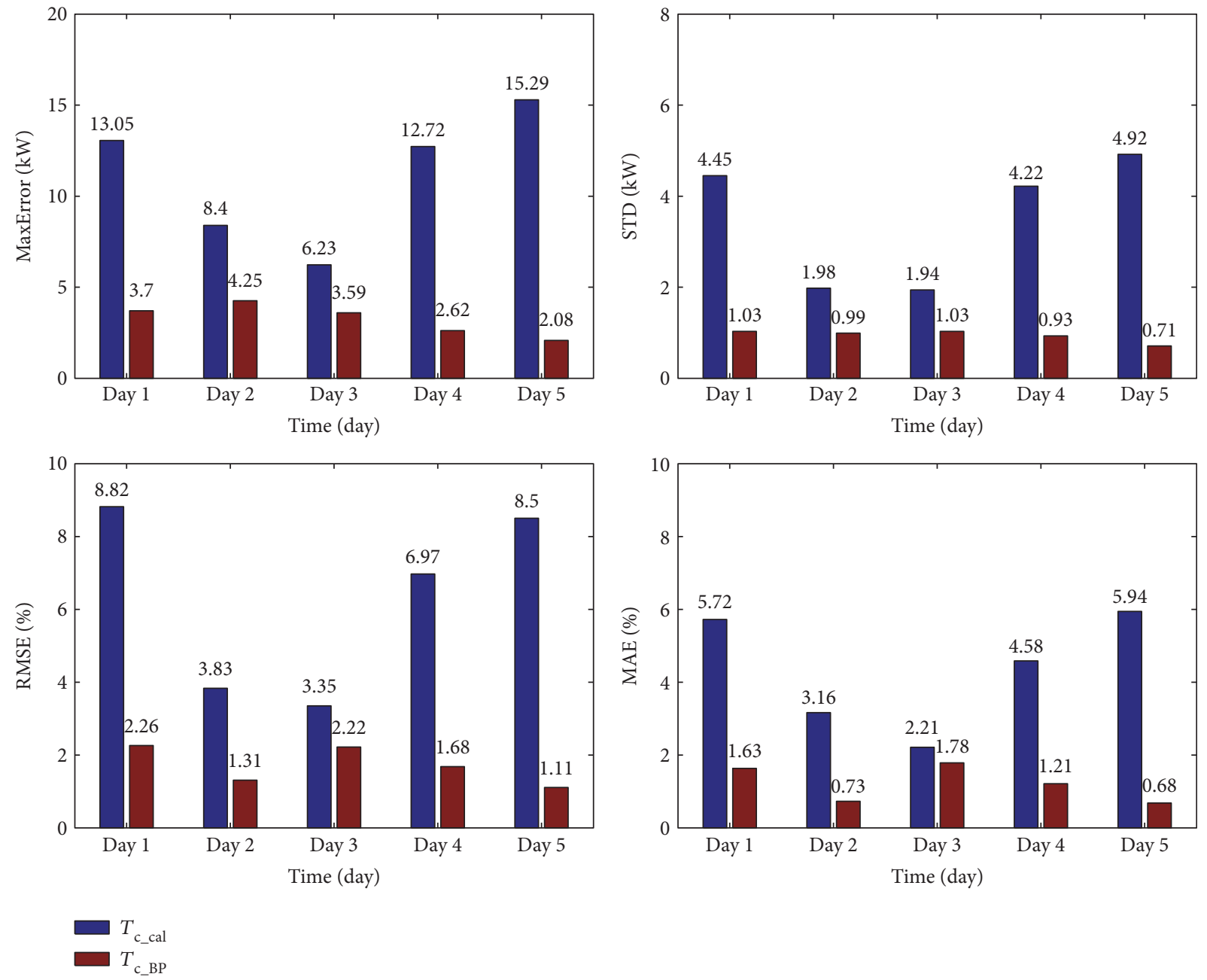

FIGURE 10: Analysis of silicon-based PV module operating temperature error.

In order to verify the accuracy and universal adaptability of the proposed model, the model is tested by the measured data of 5 consecutive days (20160224-20160228) of the PV plant. Figure 9 shows the results of the temperature modelling of the proposed method, and Table 6 and Figure 10 show the quantified statistical results.

\section{Conclusion}

The error of physics-based model is big for the calculation of operating temperature of silicon-based PV modules in engineering application. To solve this problem, the intelligent calculation method based on BP-ANN is applied to the calculation for operating temperature of silicon-based PV modules. By comparison analysis, the proposed method is proved to be effective. The following conclusions are made from the above result analyses:

(1) The intelligent calculation method based on BPANN can be applied in the calculation of PV module operating temperature, which not only has a strong self-learning ability for nonlinear objects but also utilizes the historical information of PV power plant included in the training data.

(2) Calculation method of operating temperature of PV modules based on BP-ANN realized the online softsensing operating temperature using the existing measurable parameters and can replace the temperature sensor measurement.

(3) Comparing with the physics-based model calculation method, the method proposed in the paper avoids complicated analysis process of the physics-based modelling method, so it can be applied to engineering calculations with less calculation time and higher calculation accuracy.

(4) Compared with SVM methods, BP-ANN model performs better with higher calculation accuracy and faster calculation speed.

\section{Nomenclature}

A: $\quad$ Aperture surface area of PV module $\left(\mathrm{m}^{2}\right)$

$b: \quad$ Bias 


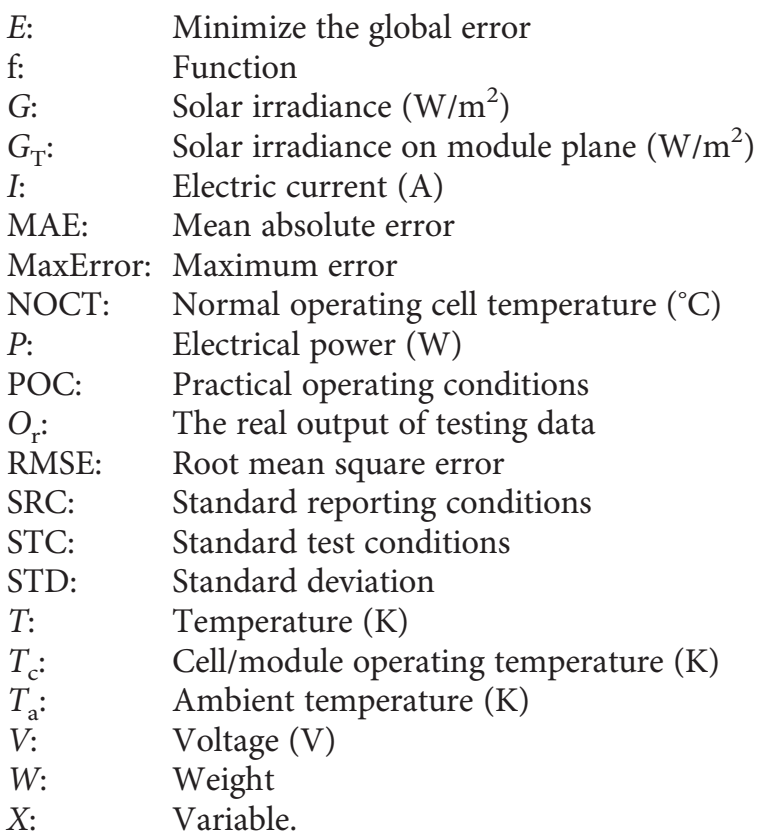

\section{Greek Letters}

$\alpha$ : Solar absorption of PV layer

$\beta$ : Temperature coefficient $\left(\mathrm{K}^{-1}\right)$

$\gamma$ : Solar radiation coefficient

$\eta$ : Cell/module electrical efficiency.

\section{Subscripts}

$\begin{array}{ll}\text { 0: } & \text { At SRC } \\ \text { a: } & \text { Ambient } \\ \text { C: } & \text { Cell (module) } \\ \text { cal: } & \text { Calculate } \\ \text { D: } & \text { Diode } \\ \text { m: } & \text { Maximum, at maximum power point } \\ \text { mean: } & \text { Average value } \\ n: & \text { Sample size } \\ \text { NOCT: } & \text { At NOCT conditions } \\ \text { obs: } & \text { Observation } \\ \text { OC: } & \text { Open circuit } \\ \text { p: } & \text { Parallel connection } \\ \text { ph: } & \text { Photogenic } \\ \text { r: } & \text { Real situation } \\ \text { ref: } & \text { Reference value, at reference conditions } \\ \text { s: } & \text { Series connection } \\ \text { SC: } & \text { Short circuit } \\ \text { T: } & \text { On module's tilted plane. }\end{array}$

\section{Conflicts of Interest}

The authors declare no conflict of interest.

\section{Authors' Contributions}

All authors contributed to this work by collaboration. Honglu Zhu is the first author in this manuscript. All authors revised and approved the final manuscript for the publication.

\section{Acknowledgments}

The authors would like to acknowledge the Fundamental Research Funds for the Central Universities (2016MS52 and 2016MS31) and the Research Funds from the State Grid Corporation of China (SGHE0000KXJS1700074).

\section{References}

[1] P. Mora Segado, J. Carretero, and M. Sidrach-de-Cardona, "Models to predict the operating temperature of different photovoltaic modules in outdoor conditions," Progress in Photovoltaics: Research and Applications, vol. 23, no. 10, pp. 1267-1282, 2014.

[2] C. Schwingshackl, M. Petitta, J. E. Wagner et al., "Wind effect on PV module temperature: analysis of different techniques for an accurate estimation," Energy Procedia, vol. 40, pp. 7786, 2013.

[3] Q. Kou, S. A. Klein, and W. A. Beckman, "A method for estimating the long-term performance of direct-coupled PV pumping systems," Solar Energy, vol. 64, no. 1-3, pp. 33-40, 1998.

[4] R. Ajdid, M. Ouassaid, and M. Maaroufi, "Power output evaluation of polycrystalline PV panel under various irradiances and temperatures in Moroccan regions," in 2015 International Conference on Electrical and Information Technologies (ICEIT), pp. 257-262, Marrakech, Morocco, 2015.

[5] B. Rupnik and O. Westbrook, "Ambient temperature correction of photovoltaic system performance data," in 2014 IEEE 40th Photovoltaic Specialist Conference (PVSC), pp. 19731977, Denver, CO, USA, 2014.

[6] C. M. Whitaker, T. U. Townsend, H. J. Wenger, A. Iliceto, G. Chimento, and F. Paletta, "Effects of irradiance and other factors on PV temperature coefficients," in The Conference Record of the Twenty-Second IEEE Photovoltaic Specialists Conference, vol. 1, pp. 608-613, Las Vegas, NV, USA, 1991.

[7] J. J. Wysocki and P. Rappaport, "Effect of temperature on photovoltaic solar energy conversion," Journal of Applied Physics, vol. 31, no. 3, pp. 571-578, 1960.

[8] E. Skoplaki and J. A. Palyvos, "On the temperature dependence of photovoltaic module electrical performance: a review of efficiency/power correlations," Solar Energy, vol. 83, no. 5, pp. 614-624, 2009.

[9] S. Nižetić, F. Grubišić-Čabo, I. Marinić-Kragić, and A. M. Papadopulos, "Experimental and numerical investigation of a backside convective cooling mechanism on photovoltaic panels," Energy, vol. 111, pp. 211-225, 2016.

[10] V. J. Chin, Z. Salam, and K. Ishaque, "Cell modelling and model parameters estimation techniques for photovoltaic simulator application: a review," Applied Energy, vol. 154, pp. 500-519, 2015.

[11] A. M. Ameen, J. Pasupuleti, and T. Khatib, "Modeling and characterization of a photovoltaic array based on actual performance using cascade-forward back propagation artificial neural network," Journal of Solar Energy Engineering, vol. 137, no. 4, article 041010, 2015.

[12] D. Jena and V. V. Ramana, "Modeling of photovoltaic system for uniform and non-uniform irradiance: a critical review," Renewable and Sustainable Energy Reviews, vol. 52, pp. 400417, 2015. 
[13] Y. Du, C. J. Fell, B. Duck et al., "Evaluation of photovoltaic panel temperature in realistic scenarios," Energy Conversion and Management, vol. 108, pp. 60-67, 2016.

[14] G. Tina, "A coupled electrical and thermal model for photovoltaic modules," Journal of Solar Energy Engineering, vol. 132, no. 2, article 024501, 2010.

[15] G. M. Tina, G. Marletta, and S. Sardella, "Multi-layer thermal models of PV modules for monitoring applications," in 2012 38th IEEE, Photovoltaic Specialists Conference (PVSC), pp. 002947-002952, Austin, TX, USA, 2012.

[16] E. Skoplaki and J. A. Palyvos, "Operating temperature of photovoltaic modules: a survey of pertinent correlations," Renewable Energy, vol. 34, no. 1, pp. 23-29, 2009.

[17] D. Faiman, "Assessing the outdoor operating temperature of photovoltaic modules," Progress in Photovoltaics: Research and Applications, vol. 16, no. 4, pp. 307-315, 2008. 

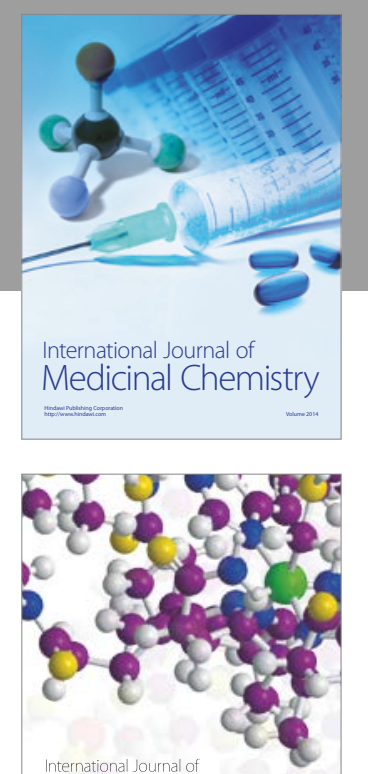

Carbohydrate Chemistry

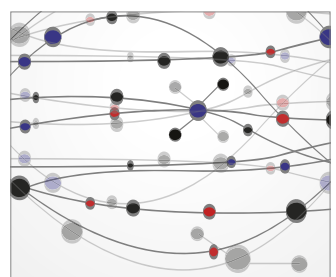

The Scientific World Journal
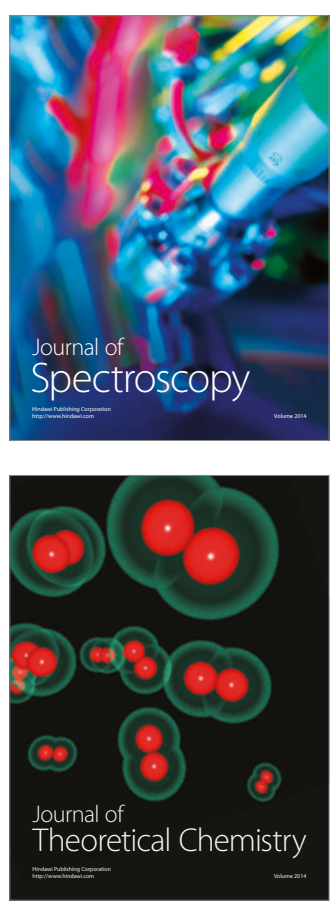
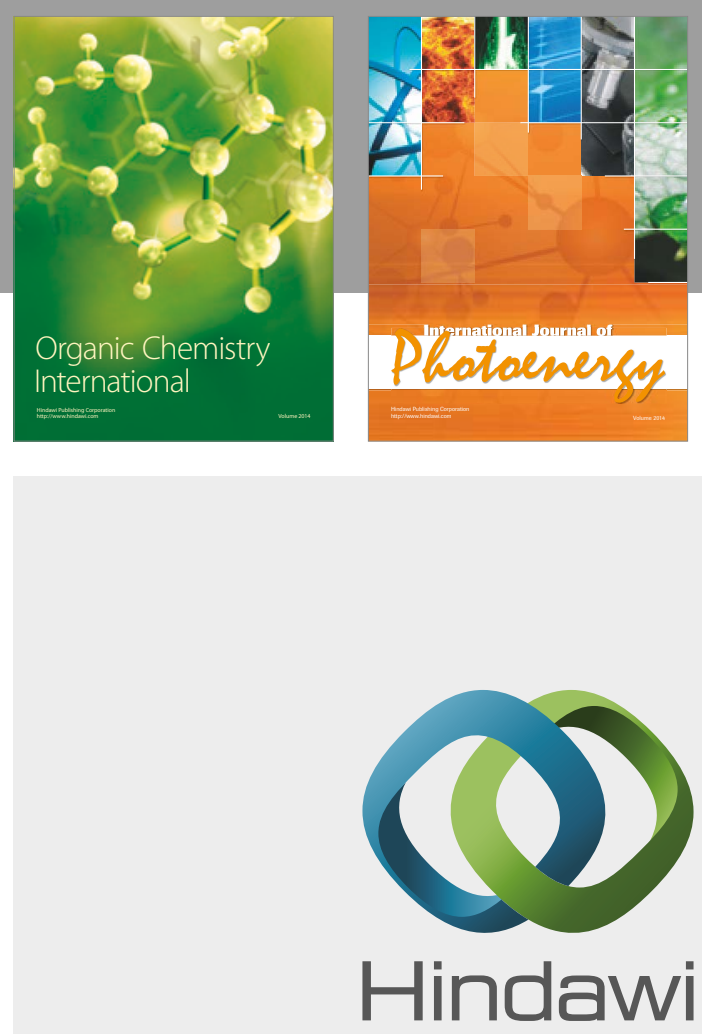

Submit your manuscripts at

https://www.hindawi.com

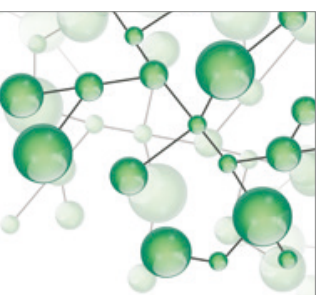

International Journal of

Inorganic Chemistry

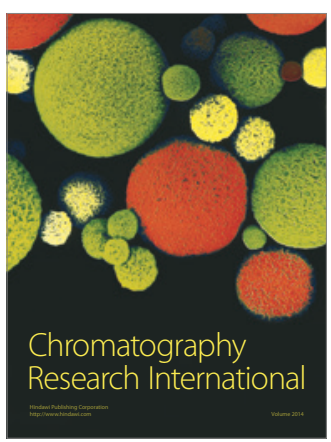

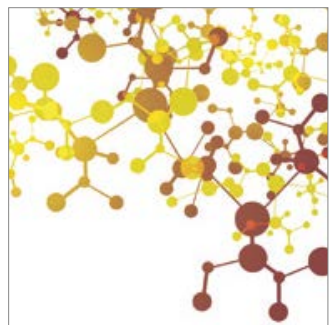

Applied Chemistry
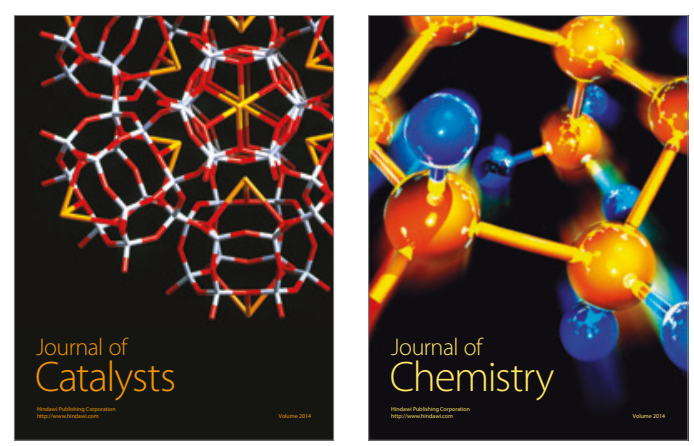
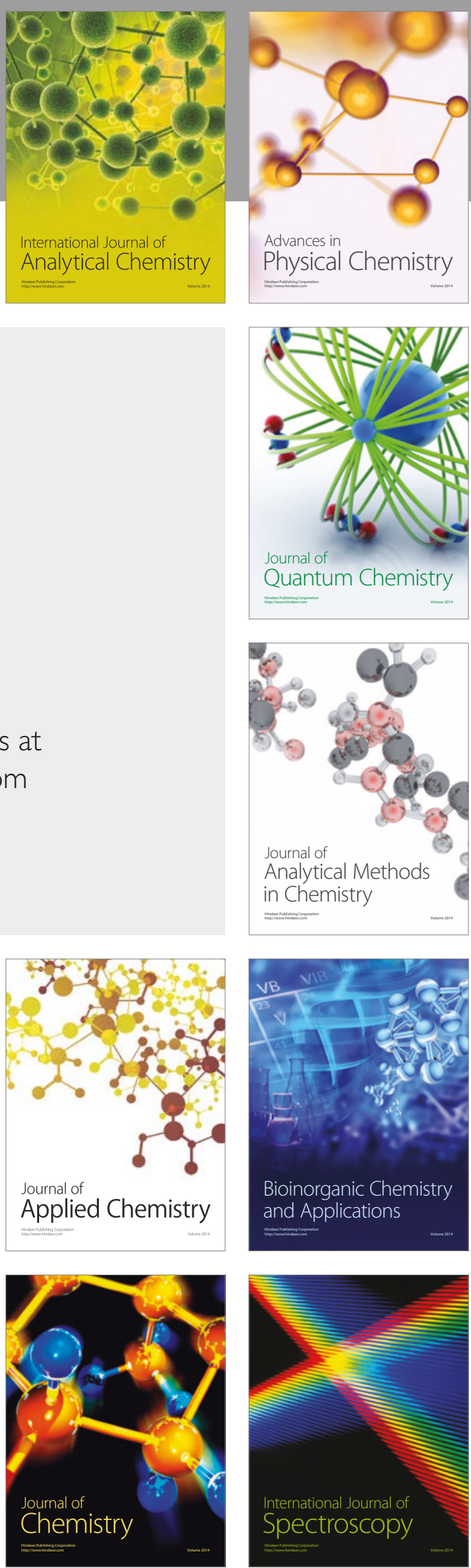